\title{
MANIFESTO A UM CURRÍCULO METAMÓRFICO
}

Alexandre Luiz Polizel, Fabiana Gomes, Moisés Alves de Oliveira

Universidade Estadual de Londrina - UEL, Programa de Pós-graduação em Ensino de Ciências e Educação Matemática, Londrina, PR. E-mail: alexandre polizel@hotmail.com

\section{RESUMO}

Neste manuscrito optamos por colocar à luz nossas inquietações sobre os currículos, inspirados pela metamorfose dos espíritos do camelo, do leão e da criança, de Nietzsche. O camelo simboliza um animal de carga, que necessita de um sacerdote que o carregue de valores, domesticando-o, ressentindo-o. O leão é um animal que vai à luta, se nega a esta carga, guerreiro e por buscar a liberdade, elege-se erudito, atribuindo a si bons valores. O espírito da criança é criativo, ingênuo, é capaz de (trans)criar valores que façam sentido a sua existência. Pensamos o currículo como artefato cultural e como tecnologias, sem atribuir a eles significados fixos e imutáveis. Sendo assim, nos manifestamos a favor de um currículo metamórfico, que esteja em transformação constante em função de suas contingências culturais.

Palavras-Chave: Educação, Currículo, Nietzsche.

\section{MANIFEST A METAMORPHIC CURRICULUM}

\begin{abstract}
In this manuscript we chose to bring to light our concerns about the curricula, inspired by the metamorphosis of the spirits of the camel, the lion and the child, of Nietzsche. The camel symbolizes a beast of burden, who needs a priest who carries him with values, taming him, resenting him. The lion is an animal that goes to the fight, if it denies to this load, warrior and for seeking the freedom, it selects itself scholar, attributing to itself good values. The child's spirit is creative, naive, it is capable of (trans) creating values that make sense of its existence. We think of the curriculum as a cultural artifact and as a technology without attaching to them fixed and immutable meanings. Therefore, we are in favor of a metamorphic curriculum that is constantly changing according to its cultural contingencies.
\end{abstract}

Keywords: Education, Curriculum, Nietzsche. 


\section{(CURRÍCULOS) ALQUÍMICOS}

Compreendemos os currículos como artefatos culturais e como tecnologias. Artefatos culturais visto que a constituição de currículos se faz em práticas culturais, as quais não apresentam significados fixos e imutáveis, mas significações contingenciais que se deslocam à medida que associações e jogos de interesses são investidos. Dessa forma, o currículo é atravessado por relações de saber-poder, tracionamentos e negociações usados para analisar, organizar, legitimar e instituir saberes tornados formativos ou não. Na eleição de saberes, nos jogos de associações e interesses, delineia-se também quais modos de existência são passíveis de serem produzidos e vividos (LATOUR, 2017; SILVA, 2015).

Neste movimento, os currículos também são lidos por nós como tecnologias, não em sentido mecânico, mas sim como movimentação e deslocamento de corpos e maquinarias que se tornam produtivos. Produzidos sob sistemas de constituição simbólicas, de significados e significações e também de dominações, na torção dos governos de si e do outro (FOUCAULT, 2014).

Neste conduto, os currículos como artefatos culturais e tecnologias culturais são produzidos no cerne das práticas culturais, mas também são capazes de as produzir. Poderíamos voltar nossos olhares a Louis Pasteur, que oferece substratos, nutrientes, gases, temperaturas a seus micróbios afetando-os, produzindo-os, ao mesmo tempo em que os micróbios devolvem crescimento, turvação, mudanças de $\mathrm{pH}$ a Pasteur - ambos produzem-se coletiva e simultaneamente (LATOUR, 2017). Poderíamos olhar também os alemães que produzem seus ginásios, organizam os corpos, tempos, saberes, experiencialidades afim de instituir uma cultura superior, produzindo seus bonecos flácidos domestificados (NIETZSCHE, 2004; 1974). Poderíamos verter o olhar sob as prisões, organizadas com postos de vigília, cadeados nas celas, visibilidades intensificadas sob os corpos aprisionados (FOUCAULT, 2014). O que seria de Pasteur sem os micróbios, dos alemães sem seus bonecos flácidos, das prisões sem os aprisionados, das práticas culturais sem os currículos? Poderíamos então falar de um currículo-cultura?

O currículo-cultura é assim, alquimista e alquímico, reúne um conjunto de elementos, de disciplinas, de saber-poder que associam um coletivo. E como alquímico-alquimia, o currículocultura é transformação constante, o fogo heraclitiano. Neste montante, levantamos um manifesto por um currículo metamórfico utilizando de marteladas a fim de trincar e instigar inquietações. Destarte, organizamos este texto em três eixos em que discutimos as três metamorfoses em Zaratustra: a) A metamorfose do camelo ressentido, onde falamos sobre o currículo que cameliza; b) A metamorfose do leão - anseio por liberdade, buscando-a sem criar novos valores, requerendo mais legitimidade para aqueles que possui; e c) A metamorfose da criança - inocências, em que se discute o espírito criança como uma potencialidade de produção.

\section{A METAMORFOSE DO CAMELO RESSENTIDO}

Como al-químicos trabalhamos com metamorfoses, transformações, caos e ordem, entropias e entalpias, matéria e energia, espaço e tempo... O Zaratustra de Friedrich Nietzsche (2016), também é alquímico, hibridiza tempos, valores, espaços, animais, corpos e espíritos. Zaratustra nos convida a pensar três transformações do espírito, que seriam também transformações do corpo a partir dos personagens conceituais: o camelo, o leão e a criança. Ele faz isto recorrendo a uma genealogia dos saberes-poderes-espaços-tempos...

Zaratustra nos faz pensar no camelo como aquele que precisa carregar peso, um espírito de carga. Espírito este voltado a uma dependência sacerdotal, um senhor que organize valores, que clame por um paraíso porvir no meio do deserto árido - mas biodiverso - da existência. Neste sentido, o camelo precisa do sacerdócio, de um "outro mundo" vazio de valores, um espaço metafísico que prometa seu descanso após carregar pesos deserto adentro. 
Este espírito tem como base seu ressentimento, que precisa renunciar a coisas aos quais é impotente sobreviver em comum acordo (NIETZSCHE, 2009). Assim, cria para si uma consciência (uma má consciência), para vigiar-se, examinar-se e castigar-se quando necessário, em seu processo de renúncia e de carregamento de pesos (NIETZSCHE, 2016; 2009; 1974; FOUCAULT, 2014). Assim, nossa primeira parada é uma primeira metamorfose que permite-nos pensar os artefatos curriculares e seus efeitos de produção. Fazemos isto lançando uma flecha, uma linha de força, uma indagação que choca-se com ídolos: Teríamos efeitos de um currículo camelo operante, nos espaços escolares e em outros movimentos educacionais? Um currículo que conclama uma metafísica, uma salvação em outro mundo, uma essência que não é deste mundo, um currículo-Deus... Para além disto, teríamos um currículo que atua vertendo pesos de carregamentos, valores adoecidos que acorrentam a existência sob as costas de corpos produzidos como camelos?

Desta forma, pensar um currículo sob a metáfora do camelo de Zaratustra é levar-nos à reflexão de que formas, que linhas de forças e que saberes são investidos sob um corpo para torna-lo camelo - neste sentido inclui-se o próprio currículo como um corpo, que é matéria e energia, parte engendrada e fluxos flutuantes. Dois movimentos nos vêm à mente: a) $\mathrm{O}$ conjunto associativo que "cameliza" um corpo são as linhas de força que transmutam-no em um corpo ressentido; b) O conjunto associativo que "cameliza" um corpo são as linhas de força que transformam seu campo de forrageio.

Os corpos ressentidos são produzidos quando são transformados em impotentes, ao serem esgotados por forças que retiram sua energia vital e colocam-no em outro plano. A transformação de um corpo ressentido é catequética, quando um sacerdote se coloca frente a um rebanho e põese a organiza-los por uma perspectiva da negação. Aprende a dizer "Não" a outros valores, métodos, formas de ser e de estar no mundo. Todavia, seus valores são frágeis e não conseguem coexistir com outras formas de pensar. Tornam-se assépticos, pois qualquer bactéria pode penetrar no rebanho e eliminar a todos - assim, passam a desejar eliminar qualquer vestígio que considerem contaminante. Logo, o corpo torna-se ressentido à medida que tem a promessa de uma vida melhor, plena, única e verdadeira, porque isso requer renúncia, regras, doutrinas, um protocolo de procedimentos que deve ser seguido à risca para ter um resultado ao final de seu percurso experiencial (NIETZSCHE, 2009; 1974). A camelização do corpo-currículo, neste montante, é o acorrentamento de um corpo que arrasta consigo o peso da "negatividade".

Todavia, o processo de camelização é também um processo orgânico e, envolve movimentos de nutrição, fisiologia e ecologia. Como sabemos, os camelos vivem em espaços desérticos ${ }^{1}$ e, o currículo e as práticas culturais podem desertificar um determinado domínio fitogeográfico. Imaginemos um espírito que transita por uma mata atlântica, com determinado tipo de alimentação, em relações ecológicas com outros organismos... Imaginemos agora este espaço ser dominado pelo sacerdócio, que transforma este hábitat, retira as diversidades de organismos e desertifica o espaço. A proposta do sacerdote é: "Mudem sua nutrição, adaptem sua fisiologia, tornem-se camelos, carreguem nosso peso pelo deserto e distribua-o".

A tentativa é a produção de uma suposta homogeneidade. Assim, teríamos que desconfiar da delineação de quadros de referências solidificantes, cheio de certezas e baseados em verdades absolutas e que são postos acima das relações. Do mesmo modo, deveríamos (des)confiar dos sacerdócios do "ensino, avaliação, aprendizagem, metodologia, didática, organização, planejamento, eficiência, objetivos..." (SILVA, 2015), colocando em questionamento: Quando estes tornam as possibilidades desérticas e acorrentam-nos a um único modo de existência?

\footnotetext{
${ }^{1}$ Reconhecemos o espaço desértico com sua biodiversidade especifica, todavia utilizamos da metáfora sob um viés nietzschiano com referência a retirada de diversidades e mudança do espaço, deixando climas e espaços secos de pulsão de vidas.

${ }^{2}$ Retiramos estas palavras de categorizações criadas por Tomaz Tadeu da Silva (2015), tem finalidade didática de pontuar uma analítica voltada as diferenciações tradicionais, críticas e pós-criticas. Se as utilizamos aqui, é como metáforas para o fazer pensar e, por vermos similitudes de tais categorias com os três personagens que utilizamos como fio condutor no percurso deste manuscrito: Camelo, Leão e a Criança.
} 
A perspectiva tradicionalista pode apresentar-se como este sacerdote, como um currículo camelizador. Suas pregações com aspectos tradicionais que imperavam nos currículos, ansiavam pela solidificação dos corpos, protagonistas de um ensino homogêneo, sem brechas, sem contaminações. O camelo arrasta em si aquela carga conceitual, aqueles valores pesados e ressentidos que fazem-se negar qualquer outro, dentro de uma pedagogia camelizadora, fixa, naturalizada - um espaço desértico.

O que está em jogo neste processo é a crença por uma Ciência com " $\mathrm{C}$ " maiúsculo (LATOUR, 2017), uma Ciência maior, instituída de uma "verdade perfeita". Uma Ciência considerada de outro mundo, que busca-se capturar. Uma Ciência-Deus, que provém de outro plano, um plano maior, o mundo das ideias onde as verdades límpidas resvalam-se como imperativos categóricos que podem ser capturadas por meio de um sistema enrijecido de ensinar, e um protocolo sagrado a ser seguido.

\section{A METAMORFOSE DO LEÃO: ANSEIO POR LIBERDADE}

O camelo se revolta e deseja ser leão. O leão anseia por liberdade, persegue-a como uma presa, busca ser senhor de seu próprio deserto e transforma-lo como bem entender. Anseia por caminhar entre os outros animais, ser um rei, ser seu próprio Deus. É aquele que aventura-se, caça, persegue, desossa... que busca lógicas e casualidades, organiza seus espaços, atribui a si valores bons, melhores, vivíveis, virtuosos. O leão é o detentor de uma moralidade nobre, senhoril, aquele que leva à sabedoria para ensinar e livrar o outro. Se o camelo (re)quer um sacerdócio, o leão elege-se erudito (NIETZSCHE, 2009).

É o leão que grita ensinando o outro a libertação: "Tu deves". Desta forma, "[...] Criar para si a liberdade e um 'não' sagrado também perante a obrigação: para tanto, meus irmãos, é necessário o leão" (NIETZSCHE, 2016, p. 43). O leão aponta então as relações de dominação, luta contra elas, quer transforma-las, mas ainda assim tem um código de conduta do ser leão. Se o camelo produz uma moralidade ressentida do "dizer não" a tudo, o leão cria a moralidade senhoril de "dizer sim" a si, apenas.

Assim, os currículos tornam-se leões e produzem corpos leões à medida que abdicam de um "sagrado" e passam a seguir suas normas próprias de conduta, ressaltando que o "sagrado" o dominava e quer-se emancipar deste sagrado. Se os camelos bradavam por "ensino, avaliação, aprendizagem, metodologia, didática, organização, planejamento, eficiência, objetivos" o leão conclama com instrumentais de sua caçada "ideologia, reprodução cultural e social, poder, classe social, capitalismo, relações sociais de produção, conscientização, emancipação, libertação, currículo oculto, resistência" (SILVA, 2015). O camelo pergunta "Como?" ao seu sacerdote, o leão pergunta a si "Para que e para que $(\mathrm{m})$ ?".

Neste sentido, o leão é a figura que questiona-se de toda reação ocorrente em sua volta, indaga-se: "Por que estou aprendendo isto? Para que estou aprendendo isto? Para quem estou aprendendo isto?" Assim, o Leão coloca-se em questionamento, sobre a utilização, o sentido da produção, a própria existência destes saberes compostos nos currículos e não outros. Os "mestres" leões, eruditos, passam a conclamar um currículo que realize contextualizações, problematizações e que sejam significativos às vivências da alcateia - sobretudo, que produza valores virtuosos.

Aqui, os leões martelam a metafisica da Ciência-Deus localizada em outro mundo, em outro plano. Todavia, compreende-se que esta Ciência continua sendo uma Ciência maior, pois ainda requer para si um estatuto de verdade e legitimidade. Ao invés desta ser uma Ciência-Deus, ela propõe-se uma Ciência-Libertação. A Ciência-libertação é conclamada por seus leões como algo que deve fazer sentir e sentido, devendo assim ter uma relação com o contexto onde os leões estão inseridos, e deve proporcionar-lhes o processo de transformação do meio em que vivem. 
O Currículo e a Ciência dos leões continuam envolvendo um endurecimento do pensamento, à medida que este elege uma pedagogia voltada a utilização, ao uso, ao próximocontexto, e a uma suposta casualidade das coisas. Continua então acorrentar-se, nas casualidades e na seleção de valores que lhes seriam uteis - libertadores.

\section{A METAMORFOSE DA CRIANÇA: INOCÊNCIAS}

Nas movimentações al-químicas e nas metamorfoses dos currículos nos perguntamos: "Por que precisa o leão predador ainda fazer-se criança?" (NIETZSCHE, 2016, p.44). O camelo carrega grandes pesos, aguenta viver na desertificação e seguir seu sacerdote. O leão, é um caçador nato, que batalha, valora-se, e busca a libertação de si. Mas o que faz a criança?

"Inocência é a criança, esquecimento, recomeço, um jogo, uma roda que gira a partir de si mesma, um primeiro movimento, um sagrado dizer sim" (NIETZSCHE, 2016, p.44). Neste sentido, a criança entrega-se, descobre, vasculha, sente, brinca, ri, chora, faz parte deste mundo onde essa faz sua ciranda. A criança seria o espírito livre, não por que está em libertação, mas por que "diz sim", e este "sim" não é apenas a si, mas à multiplicidade, às diferenças, ao desconhecimento, ao acontecimento. A criança é a única criadora de valores, pois em sua inocência e esquecimentos não busca colonizar o Outro. Quando a ela olha para o camelo, ela ri; quando olha para o leão, ela ri e, quando olha para si, ela ri de si mesma. Seu riso é que coloca as dúvidas e os questionamentos em movimentação, ela pergunta ironicamente: "Para que e para quem serve estes valores mesmo?"

A criança é a que se entende no agora, no presente e na incerteza do futuro. Os currículos que produzem(-se) crianças ao nosso ver centram-se nas "identidades, alteridades, diferenças, subjetividades, significações, discursos, saberes-poderes, representações, culturas, gênero, raça, etnia, sexualidade, estranhamentos..." (SILVA, 2015). Utiliza-se destas máscaras para fazer-se outra, é para o reconhecimento de multiplicidades de potencialidades e não para servir em um rebanho ou libertar o outro criando "deveres".

A criança não quer ser governada por um sacerdócio, tão pouco quer a libertação do outro de acordo com seus valores próprios, a criança vive os acontecimentos do presente, vive estes, ama estes como parte constituinte de seu destino. A criança experimenta, interpreta, faz sentir. A criança transforma-se continuamente, e seu devir é um devir criança. Tudo para a criança é novo, intenso, espantoso, tudo é como se fosse pela primeira vez. A criança é muito inocente para submeter-se a regras criadas pelos sacerdotes ou pelos leões, por seus limites e normatizações. Ela não separa realidade-ficção, este mundo de outro. Ela cria, fantasia, se máscara e, quando se machuca, vive a dor (NIETZSCHE, 2016). É a criança que (trans)cria valores, o camelo e o leão se apropriam deles.

Mas seria possível um currículo criança? Uma ciência criança? Talvez este seja o maior desafio para pensar o currículo: a criança. Destarte, vemos o pensar um currículo-criança como um pensar sob uma perspectiva pós-critica (SILVA, 2015), de modo que as diferenças, os estranhamentos, as multiplicidades e as propagações são seus mecanismos pedagógicos. Se pensarmos em um currículo-criança, não conseguimos fazer-lhe pensando em uma Ciência com " $C$ " maiúsculo, em uma ciência maior, institucionalizada, que promete salvação para quem seguir suas virtudes. Ciência-Deus, Ciência-Libertação não fazem sentido para as crianças, elas pensam em multiplicidade (NIETZSCHE, 2016), ciências múltiplas com "c" minúsculo (LATOUR, 2017), ciências menores (NIETZSCHE, 2016; LAROSSA, 2002). Essas ciências são cambiantes pelo mundo, e em cada local, cada acontecimento-contingencia tem um estatuto diferente que a confere como ciência naquele espaço, naquele acontecimento. 


\section{CONSIDERAÇÕES}

Fomos imersos em currículos ditos tradicionais, o que nos fez pensar no espírito do camelo. Um currículo imposto, indiscutível, fixo e imutável que produzia corpos ressentidos a partir de movimentos solidificantes. A figura do camelo nos remonta a um animal de carga, aquele que carrega valores frágeis incapazes de coexistir com diferentes formas de pensar e estar no mundo. Por sua fragilidade, recorre a outro mundo, a um Currículo-Deus, uma Ciência-Deus.

A transformação de um currículo tradicional a um currículo crítico permite-nos vislumbrar uma outra forma de pedagogia. Algo no sentido de provocar no estudante questionar-se sobre o mundo e sobre as coisas desse mundo. O leão nega-se a aceitar tudo de pronto e àqueles valores outrora impostos quando camelo por regimes sacrais. O conhecimento passa a ser contestado, testado e reconstruído. Todavia, o leão torna-se um erudito, ainda segue uma "Verdade" maior que seria o caminho da "libertação" de si e dos outros. O leão não aguenta estar aprisionado a uma figura divina, e cria para si então um Currículo-Libertação, uma Ciência-libertação. A sacralidade não está mais nos céus, está na afirmação de si, nas suas virtudes e capacidades de transformação do mundo.

A criança que surge no terceiro momento, remonta a inocência, o esquecimento, as experimentações. Ela, movida pela criatividade e por seus sentidos, experimenta e transvalora. A única que não se apropria de valores, mas os cria em cada encontro. A criança não compreende as regras, as normas e os limites que seguem o camelo e o leão, ela é muito inocente para isto. Assim, a criança borra fronteiras, atravessa-as, movimenta-se, ela dança, ri e festeja. Em sua doçura, a criança não visualiza um Currículo, uma Ciência, mas uma multiplicidade de diferentes currículos e ciências. Para nós, al-químicos, esta é a inquietação que nos move: Quais os movimentos para a terceira metamorfose?

Reiteramos, que lançamos não da metáfora Nietzscheana para tratarmos o currículo como um artefato-técnica metamórfico, não é unicamente camelo, leão ou criança, mas um constante deslocamento composicional que mobilizam os três modos de ser - os três modos produtivos. Demarcar estes personagens, é sugestionar eixos analíticos para estudos curriculares.

\section{REFERÊNCIAS}

FOUCAULT, M. Vigiar e punir: Nascimento da prisão. 42 ed. Petrópolis-RJ: Vozes, 2014.

LAROSSA, J. Nietzsche \& a Educação. Belo Horizonte: Autêntica, 2002.

LATOUR, B. A esperança de Pandora: Ensaios sobre a realidade dos estudos cientificos. São Paulo: UNESP, 2017.

NIETZSCHE, F. Assim falou Zaratustra: um livro para todos e para ninguém. Porto Alegre: L\&PM, 2016.

. Genealogia da moral: uma polêmica. São Paulo: Companhia das letras, 2009.

. Escritos sobre Educação. Tradução de Noéli Correia de Melo Sobrinho. Rio de Janeiro: Ed. PUC-Rio; São Paulo: Loyola, 2004.

. Obras incompletas. São Paulo: Abril Cultural, 1974.

SILVA, T.T. Documentos de Identidade: uma introdução às teorias do currículo. Belo Horizonte: Autêntica, 2015. 